\title{
Digitalization of historic buildings using modern technologies and tools
}

\author{
Anna Prokop ${ }^{1}$, Piotr Nazarko², Leonard Ziemiański ${ }^{3}$ \\ ${ }^{1}$ Department of Architectural Design and Engineering Graphics; Faculty of Civil and Environmental \\ Engineering and Architecture; Rzeszow University of Technology; \\ 12 Powstańców Warszawy Av, 35-959 Rzeszów, Poland; \\ a.prokop@prz.edu.pl (iD 0000-0003-2666-1002 \\ ${ }^{2}$ Department of Structural Mechanics; Faculty of Civil and Environmental Engineering and \\ Architecture; Rzeszow University of Technology; \\ 12 Powstańców Warszawy Av, 35-959 Rzeszów, Poland; \\ pnazarko@prz.edu.pl (iD)0000-0002-6135-2486 \\ ${ }^{3}$ Department of Structural Mechanics; Faculty of Civil and Environmental Engineering and \\ Architecture; Rzeszow University of Technology; \\ 12 Powstańców Warszawy Av, 35-959 Rzeszów, Poland; \\ ziele@prz.edu.pl (ID 0000-0002-4012-0002
}

\begin{abstract}
The aim of the paper is to present some experiences of using modern technologies to historical buildings digitalization. The emphasis is placed on the possibilities of spatial data collecting, as well as on subsequent 3D modelling. The paper describes the proposed survey techniques which are based on the Terrestrial Laser Scanning and photogrammetry. The authors obtained the point cloud by using the laser scanner Faro Focus 3D and dedicated software to combine scans (target based and cloud to cloud methods). The paper also provides an introduction to issues related to a method of building structure modelling based on a point cloud. The authors proposed some computer software tools that could improve work with a point cloud and the modelling process. The resulting 3D model could be both a source of information about historical building and a sufficient base to create computational model with spatial finite elements. The subject of the case study is the St. Hubert Chapel located in Rzeszów (Poland) and built in the middle of the 18th century under the patronage of the Lubomirski family. This rococo chapel is one of the most valuable architectural monuments in the region. Historical Building Information Model (HBIM) could be helpful in analysis, visualisations and conservation practice of this precious monument. Diagnosing the current object state and assessing its technical condition could be the purpose of creating a computational FEM model.

Keywords: digitalization of heritage buildings, laser scanning, Historical Building Information Modelling, point cloud, 3D modelling
\end{abstract}




\section{Introduction}

Monuments and heritage structures are an important factor for the economic development of many countries. The protection of monuments includes all actions taken to preserve their values and enable the society to use them. This protection can be equated with the concept of historical buildings conservation. Their preservation and maintenance require a balance between architectural values and construction safety [1]-[4].

When rapid changes take place in the world, heritage conservation should be multidisciplinary, as well as tools and methods should reflect scientific progress [5]. Laser scanning technology is emerging as a potential opportunity to be utilised in this area.

The main purpose of the paper is to present the possibility of applying reverse engineering in analysis and monuments conservation practice.

The case study presented in this paper is the St. Hubert Chapel in Rzeszów (Poland), an eighteenth-century sacral building from the rococo period. Digitalization of this object is important to preserve its cultural heritage and promote this monument in the region.

In the paper the authors used reverse engineering to create a solid model of the chapel from the TLS data. The 3D model contains information about geometry of the elements. The implementation of a BIM idea to this model allows to obtain a dataset of information and current documentation, which would be useful during maintenance and restoration of this building. In the future this model could be used for various types of analysis, for example structural stability analysis because of the railway line nearby.

\section{Methodology}

This paper presents some experiences of 3D structure modelling of a historical heritage building. The combination of contactless, non-invasive measurement techniques together with Building Information Modelling (BIM) and the finite element method can be an excellent tool for digitizing cultural heritage, assessing technical condition and determining ways to strengthen and secure the structure.

In accordance with the regulation, laser scanning is a method of terrain surface imaging, consisting in measuring the distance between the measured object and the device (scanner). The scanner can be installed on an aircraft, car or stationary structure, emitting and receiving laser pulses reflected from the object [6].

The scanner sends a laser beam towards the object (Fig. 1), which reflects it back to the device. Distance, vertical angle and horizontal angle are polar coordinates, which are then converted into the Cartesian system. 

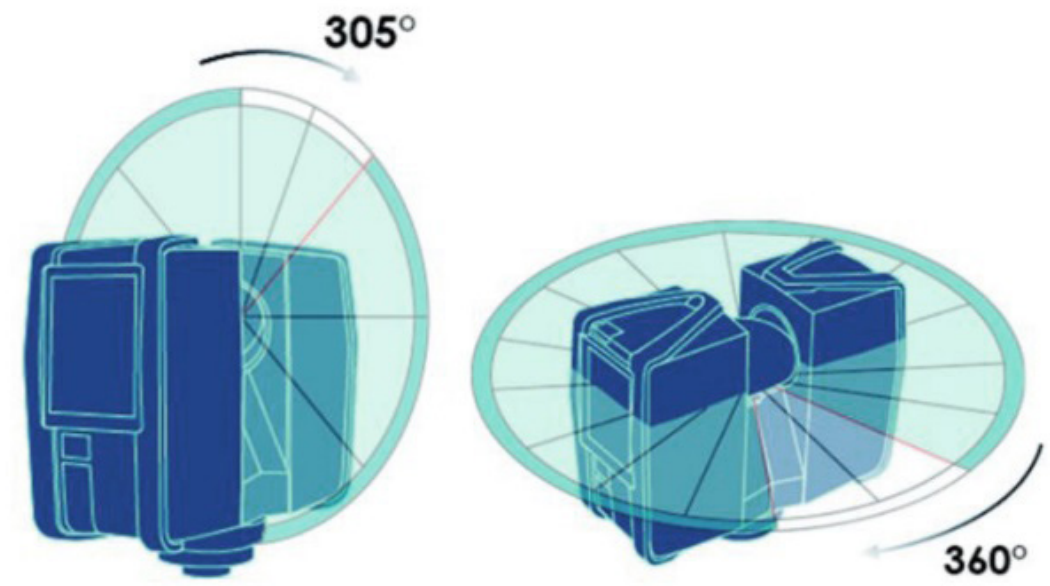

Fig. 1. Vertical and horizontal measuring range of the laser scanner used [7]

The measurement result of laser scanning technology is a point cloud - a set of measured points of space with coordinates ( $x, y, z)$. Points can contain information about the RGB colour. Their number depends on the quality settings for scanning and measurement time [7].

In order to create a point cloud for the whole measured object, it is necessary to combine individual scans (or measurements) taken from various positions by using dedicated software. The point cloud is a source of information about the object, its dimensions, geometry and colours.

The process of matching scans can be manual, semi - automatic or automatic. Much research has been carried out in automatic registration scans. Efforts have been made to create algorithms which merge scans without using the reference point as landmarks, targets and with small overlapped area to make registration faster and less data gathering time consuming without reducing accuracy [8].

Photogrammetry is another source of obtaining a point cloud. This is a field of technical sciences dealing with the acquisition, transformation, presentation and collection of information (quantitative and qualitative) related to the site (or object) based on photogrammetric photos (the so-called photograms) or their digital representations [9]. With this method, the accuracy of the resulting image -based point cloud is lower than that generated by the scanners [10].

The source of a point cloud could be also a combination of laser scanning and photogrammetry. These two methods of mapping space allow combining their advantages. Laser scanning ensures the accuracy of measured points, whereas photogrammetry ensures the accuracy of color reproduction [11]. Computer programs allow combining object photos and create a point cloud based on them. One of such programs is ReCap Photo, which processes photographs to create $3 \mathrm{D}$ representations of current sites or objects conditions. It allows creating and editing a point cloud based on both photographs and laser scans.

Point clouds can be used as a design background in programs such as AutoCAD, Navisworks or Inventor Professional. In 3D modelling programs, for example Revit or Archicad, the point cloud is a base layout for which it is possible to set views of projections, sections, perspectives or axonometry.

Inventorying by laser scanning technology allows to maintain a high level of detail, therefore using this technology for inventory of historic buildings allows digitalizing their 
complex, intricate shapes (often with irregular walls, haunches and curvatures) in 3D. These modern methods can also be used to create technical documentation for existing buildings in a process called reverse engineering $[1,12,13]$. Comparison of the point cloud with $3 \mathrm{D}$ CAD model allows for use in as-built modelling [14].

Reverse engineering largely allows to restore knowledge about the building and to adopt its management strategy. This technology, combined with parametric object modelling, is extremely useful for modernization, renovation and conservation of architectural monuments.

Designs of new buildings are increasingly based on the ideas of BIM (Building Information Modelling). It gives the possibility of accurate planning of the entire investment, making cost estimates or work schedules as well as easier coordination of all involved industries. The BIM idea can also be applied to existing buildings. This is especially important for historic buildings with or without the outdated documentation - it is called the HBIM (Historical Building Information Model) [3]. The main requirement to use BIM for the analysis and representation of historical objects (HBIM) is the high model quality and reliability regarding to its geometry.

After receiving the point cloud, a further step is a process of object modelling. Possible methods, for example in Revit, are manual modelling (a time-consuming and labour-intensive process) or the use of program add-ons (accelerating the work in automatic or semi-automatic way). Examples of such solutions are: As-Built for AutoCAD Software, As-Built for Autodesk Revit, VirtuSurv. The As-Built (FARO) software provides a whole range of advanced tools for analysis and modelling based on a point cloud data directly in AutoCAD and Revit. It contains among others features such as: automatic polyline matching, creating 2D projections using automatic line extraction, matching cylinders and planes to point groups or drawing and dimensioning building elements (for instance windows, doors or staircases). Moreover, it allows to generate detailed images by expanding point clouds and photos into the plane (for example towers, arches, frescoes on the vaults and external facades) or to adjust and align walls, pipes and planes inside the generated point cloud. VirtuSurv software enables to process photographic laser scans containing a large amount of graphic data as well as drawing which use coordinates sent directly from the scan view [12,15]. Academic and industrial research make efforts towards to fully automated recognition scans and extract CAD objects from point cloud to BIM models or 3D as-built models $[10,16]$.

From the created geometric model in Revit, it is possible to generate projections, cross-sections, elevations, 3D views and statements of data needed to complete the technical documentation of the modelled object.

The geometric model can be used as the basis for generating a computational model. The possibilities of exporting the Revit file format are as follows:

- Files in CAD format (.dwg). Exporting the solid model enables its import into FEM calculations programs. The advantage of this approach is the ability to use solid modelling to recreate the existing state of the object. After importing the file into the FEM program, it is necessary to suitably prepare the solid model for the discretization process.

- Automatic export between Revit and ARSA (Autodesk Robot Structural Analysis)/ RFEM. During physical modelling, elements marked as structural (for instance beam, column, wall, slab, foundation) automatically contain the analytical models that are transferred to calculation programs. Such an analytical model is ready for discretiza- 
tion. It is greatly useful for modelling newly designed objects due to the ideal state of geometry assumptions. In the case of existing objects, it is necessary to idealize the existing state regarding to the fact that structural elements were used only at the stage of modelling. For historical objects with complicated, irregular geometry, it may be necessary to use solid modelling elements that do not contain analytical models. Regarding structural elements, there is a need to create them in the calculation program using its tools and appropriate finite elements.

The authors used laser scanning (Faro Focus 3D) to survey the chapel outside and inside. Targets such as spheres and checkerboards were used as reference points. Individual scans were combined by using dedicated Faro Scene software. The point cloud was obtained by merging scans with target based and cloud to cloud methods. The model of building was done manually in Revit on the point cloud. Structural elements (walls, slabs) and solid blocks were used to create the model of the chapel. Then the project was exported to ARSA. Better results were obtained when the model was exported to a dwg file and imported into FEM program - ANSYS. A detailed description of the procedure and settings are presented in the "Case study" section.

\section{The case study of St. Hubert Chapel}

The process of 3D scanning and HBIM discussed in this paper are based on the St. Hubert Chapel located in Rzeszów (Poland) (Fig. 2). The chapel is a rococo building and it was built in the mid-18th century. The monument has a central system on an eight-sided projection. The eastern, western, southern and northern sides are developed into rectangular apsis. The chapel is arched with a dome. The structure is a brick wall with limestone mortar. It is plastered on both sides (Fig. 3).

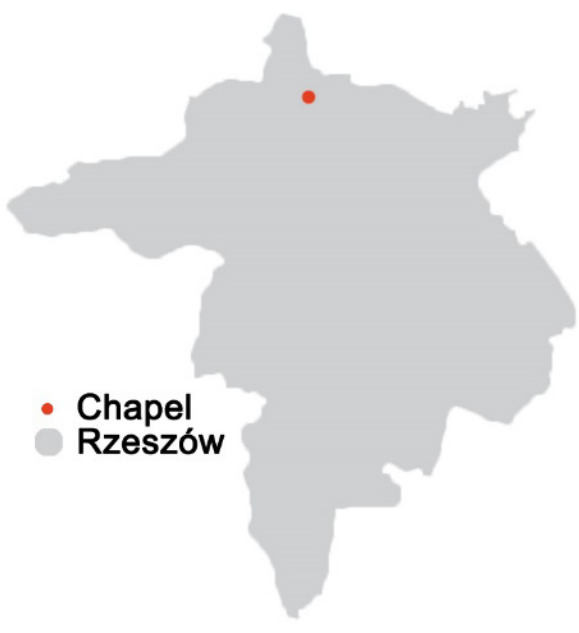

Fig. 2. Location the St. Hubert Chapel in Rzeszów

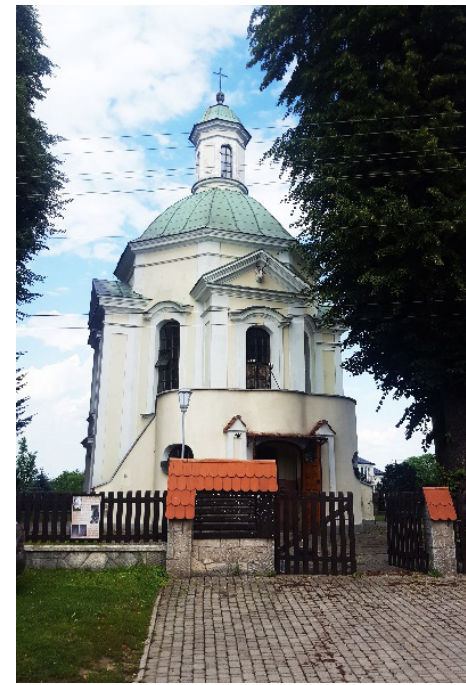

Fig. 3. The St. Hubert Chapel

The St. Hubert Chapel, also known as the Hunting Chapel, is one of the most valuable architectural monuments in the region. It was built during the Lubomirski patronage period. St. Hubert Chapel was built in the forest. It was a favourite hunting place of gentlemen from 
Rzeszów. The chapel was forgotten after the fall of the Lubomirski latifundium in the late 18th century. Around mid-19th century it was already heavily devastated. Settlements developed in this area in the next decades. The chapel functioned as a parish church in Miłocin. On all sides the chapel is surrounded by farm buildings and arable fields. The chapel is situated on a circular plot, surrounded by a wreath of trees. The entrance to the church grounds is from the road leading through the village. After the construction of a new parish church (early $21 \mathrm{st}$ century), the chapel stands unused. In the years 2010-2011, it was possible to renovate the window and door joinery, lightning protection and facade. In the years 2011-2012 and from 2014, conservation works were carried out on the wall paintings in the dome and on the walls of the nave of the altar with the illusionist painting of St. Hubert. In 2018, conservation works were carried out on the dome [17-19].

The starting point of the research was data collection, carried out with contactless surveying methods - laser scanner (Terrestrial Laser Scanning). Point clouds were obtained with a laser scanner Faro Focus 3D. It was selected scanning profiles „Outdoor $20 \mathrm{~m} . . . ”$ and "Indoor $10 \mathrm{~m} . .$. " and scan registration in colour. In the scanner software the resolution was set to $1 / 4$ for outdoors measurements and $1 / 5$ for indoor measurements. In real numbers it means $6.136 \mathrm{~mm} / 10 \mathrm{~m}\left(10240 \mathrm{pt} / 360^{\circ}\right)$ and $7.67 \mathrm{~mm} / 10 \mathrm{~m}\left(8192 \mathrm{pt} / 360^{\circ}\right)$ respectively, where point distance $\mathrm{mm} / 10 \mathrm{~m}$ is the distance between the captured scan points in $\mathrm{mm}$ with respect to a scan distance of 10 meters. The device had the measuring speed of 122000 points/s. Size of the scan in points (horizontally x vertically) was 10242 x 4339 for outdoor and $8196 \times 3471$ for indoor. A set of 10 outdoor measuring stations were planned (Fig. 4).

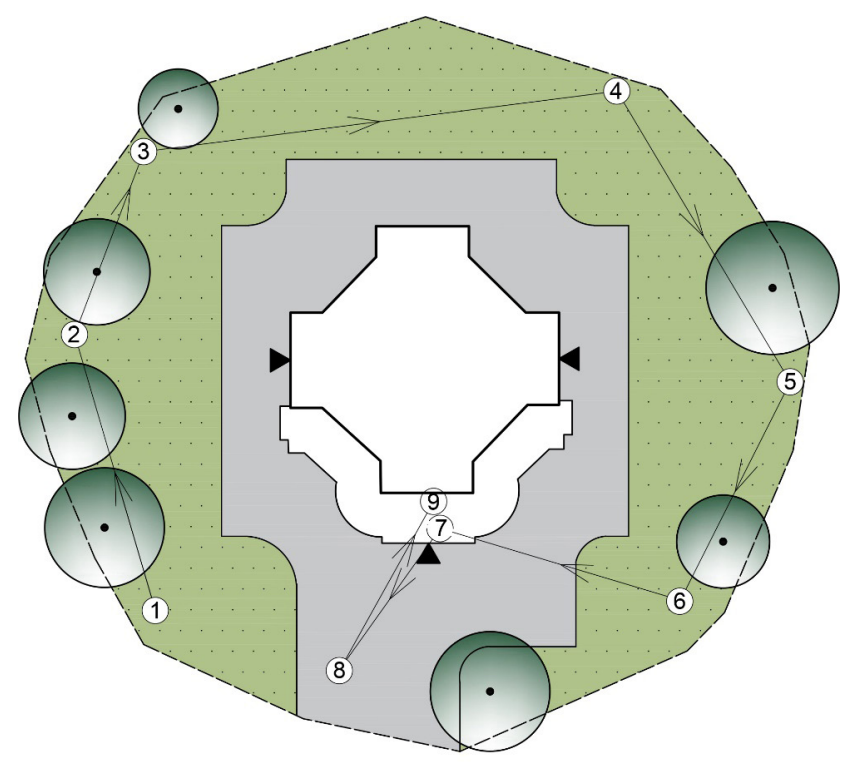

Fig. 4. Location of measuring stations (1-10) outside the building 
Measurements were made outside and inside the building (Fig. 5a, b). Due to ongoing conservation work, inside measurements were hampered by scaffolding set from floor to dome (Fig. 5c). For this reason, 13 measuring stations were required inside the building. Reference points such as spheres and checkerboards were used.

a)

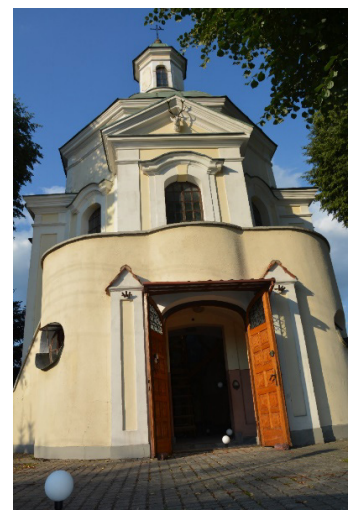

b)

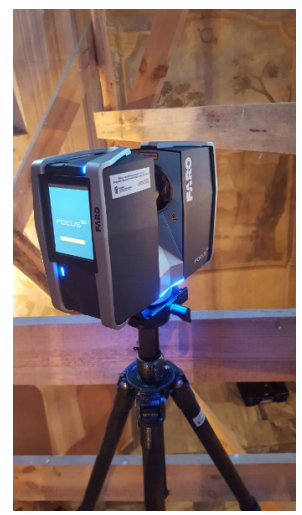

c)

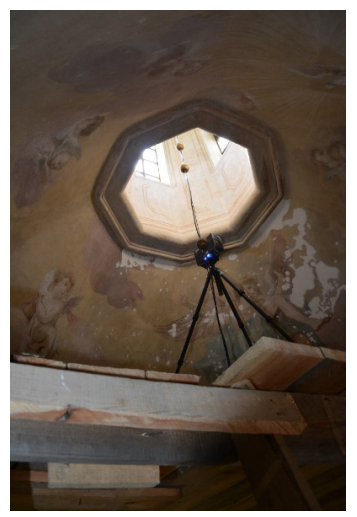

Fig. 5. Measurements with the Faro Focus 3D scanner: a) outside, b-c) inside

In this case 23 terrestrial scans were registered through Faro Scene. The scans were combined using the semi-automatic and manual methods (Fig. 6a, b). Reference points like spheres and checkerboards were detected automatically. Outer scans and scans in the basement have well measured targets so registration was target based. Additionally for inner scans, it was necessary to manually detect the reference planes and the registration method was cloudto-cloud. To merge outer and inner clusters of scans cloud-to-cloud matching was used. In cloud to cloud subsampling average point distance after uniform subsampling of scans was $10 \mathrm{~mm}$. The maximum number of iterations allowed for the algorithm to find the best solution is 30 iterations. The registered point cloud was composed of 3.273 milion points and the obtained mean point error was equal to $2.1 \mathrm{~mm}$.

a)

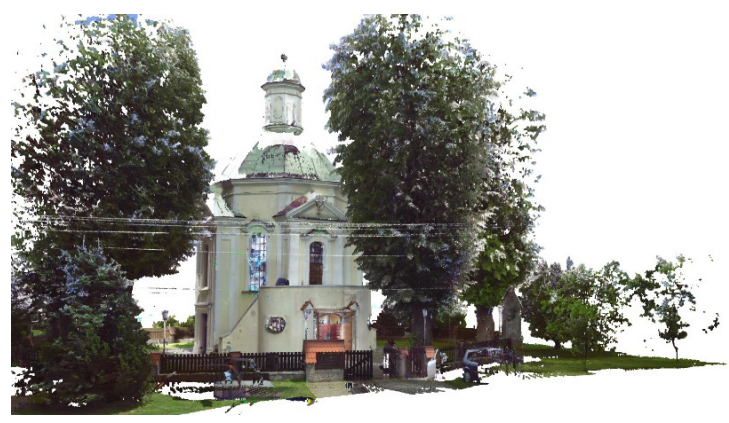

b)

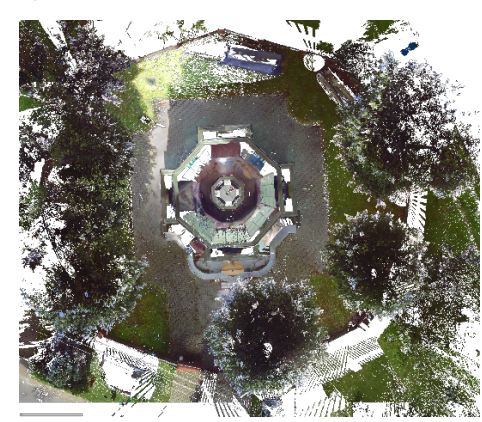

Fig. 6. Point cloud after connection in Faro Scene: a) perspective, b) top view 
Geometric model (architectural and structural) was created in Autodesk Revit. Modelling was done manually. Initially, in modelling the use of structural elements (walls, slabs) was attempted in order to transfer their analytical properties after exporting project to ARSA (Autodesk Robot Structural Analysis). Unfortunately, Revit does not contain the family of structural elements related to dome structures. Its remodelling in ARSA (with $8^{\text {th }}$ solid curve panels) allowed to obtain FEM model, but it could not be uploaded to Revit in order to show the dome architecture.

a)

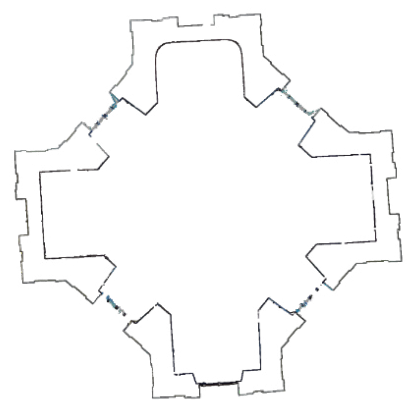

b)

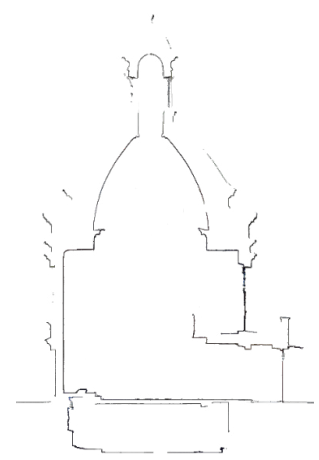

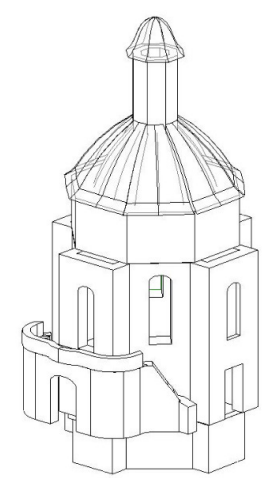

Fig. 8. Geometric solid model in Revit

Fig. 7. View from point cloud: a) projection, b) cross section

Finally, it was not possible to fully match the architectural and computational model obtained in Revit and ARSA. In the future work, due to the quite complicated geometry of this historical building (Fig. 7a, b), it would probably be necessary to manually idealize geometry after all.

The next stage was to use solid modelling, which allowed to recreate the object geometry (Fig. 8). Problems and difficulties with modelling were caused by the irregular geometry of the object (for example, a problem associated with joining walls, vertical walls deviation or mapping niches in the walls). Despite the assumptions of the chapel's design as a symmetrical object, the actual state of the object is asymmetrical, which probably results from the execution inaccuracies during the construction of the object. These aspects increased the labour-intensiveness of chapel modelling. 


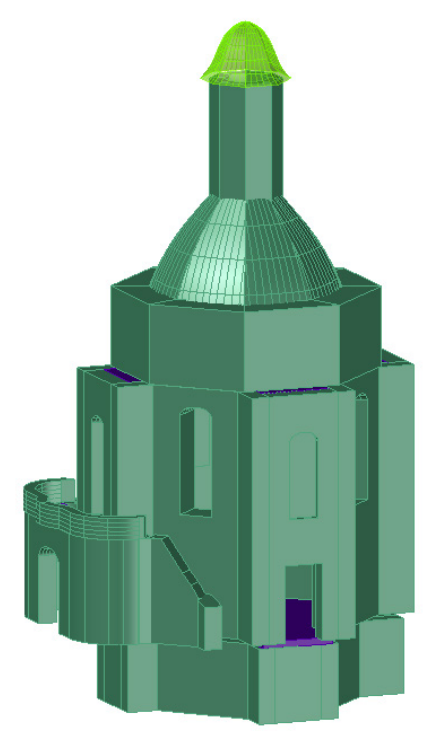

Fig. 9. Export of solid model to .dwg format

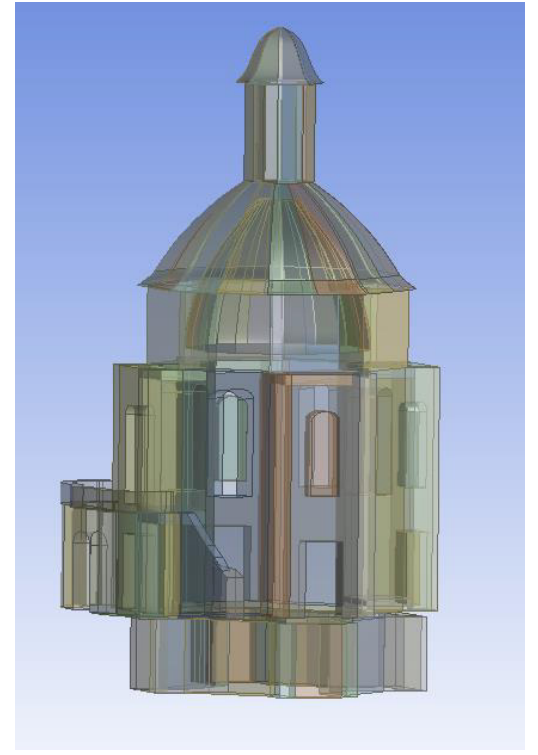

Fig. 10. Import of solid model into Ansys

Finally, the solid blocks were exported to a .dwg file (Fig. 9) which enables their further processing and discretization in FEM programs (Ansys or Inventor). In this case, a geometrical model defined in Revit was exported to ANSYS (Fig. 10). This way, a very precise computational model with spatial finite elements can be obtained and used for static or dynamic analyses.

\section{Conclusions}

Point clouds are definitely a good source of information about a historical building, especially when there is no existing documentation or it is unavailable. Point clouds can be archived and reused when needed.

The authors encountered some difficulties during the measurements inside the chapel. The reason was the ongoing conservation work. The solution was adding more measuring stations, also on the scaffolding from the floor to the dome.

Problems with modelling of the chapel were caused by the irregular geometry (irregular dome, off-centre lantern, complex staircase geometry). It increased the labour-intensiveness of the modelling process. The use of only construction elements such as walls or slabs has failed to reproduce the existing geometry. Solid modelling was a helpful strategy. The applied manual modelling is time-consuming. Automatic or semi-automatic methods would accelerate this process but their application was not considered in this paper.

The HBIM model contains full engineering drawings (projections, sections, details) for the conservation of historic structures. Moreover, it also includes 3D and orthographic documentation.

Obtaining a computational FEM model consistent with the actual state of the structure elements is a complex task. It requires taking into consideration many factors, which is the goal of the further research. Obtaining a computational FEM model that illustrates the real work of the structure allows diagnosing the current object state and designing necessary 
structure reinforcements. Repeating this process periodically may allow monitoring structural health of historic buildings.

\section{References}

[1] Biagini C., Capone P., Donato V., Facchini N., "Towards the BIM implementation for historical building restoration sites", Automation in Construction, vol. 71, 2016, pp. $74-86$. https://doi. org/10.1016/j.autcon.2016.03.003

[2] Barazzetti L., Banfi F., Brumana R. et al., "Cloud-to-BIM-to-FEM: Structural simulation with accurate historic BIM from laser scans", Simulation Modelling Practice and Theory, vol. 57, 2015, pp. 71 - 87. https://doi.org/10.1016/j.simpat.2015.06.004

[3] Quattrini R., Malinverni E.S., Clini P., Nespeca R., Orlietti E., "From TLS To HBIM. High quality semantically-aware 3D modeling of complex architecture", ISPRS - International Archives of the Photogrammetry, Remote Sensing and Spatial Information Sciences, vol. XL-5/W4, 2015, pp. 367-374. https://doi.org/10.5194/isprsarchives-XL-5-W4-367-2015

[4] Guarnieri A., Fissore F., Masiero A., Vettore A., "From TLS Survey to 3d Solid Modeling for Documentation of Built Heritage: the Case Study of Porta Savonarola in Padua", ISPRS - International Archives of the Photogrammetry, Remote Sensing and Spatial Information Sciences, volume XLII-2/W5, 2017, pp. 303-308. https://doi.org/10.5194/isprs-archives-XLII-2-W5-303-2017

[5] Gosztyła M., Jagieła B., Metodologia konserwacji zabytków architektury w praktyce. Rzeszów, 2015.

[6] Regulation of the Minister of Internal Affairs and Administration of 9 November 2011 on the technical standards for carrying out situational and altimetric surveying and for developing and transferring the results of such measurements to the state geodetic and cartographic resource.

[7] FARO Technologies Inc., "FARO Laser Scanner Focus 3D Manual", February 2013. Available: https://faro.app.box.com/s/kfpwjofogeegocr7 mf2s866s2qalnaqw [Accessed: 18 Dec 2020]

[8] Kim P., Chen J., Cho Y., “Automated Point Clouds Registration using Visual and Planar Features for Construction Environments", ASCE Journal of Computing in Civil Engineering, volume 32, 2017. https://doi.org/10.1061/\%28ASCE\%29CP.1943-5487.0000720

[9] "Fotogrametria", in: Encyclopaedia PWN. Available: https://encyklopedia.pwn.pl/haslo/fotogrametria;3902234.html [Accessed: 01 May 2021]

[10] Golparvar-Fard M., Bohn J., Teizer J., Savarese S., Peña-Mora F., "Evaluation of image-based modeling and laser scanning accuracy for emerging automated performance monitoring techniques", Automation in Construction, volume 20, issue 8, 2011, pp. 1143-1155. https://doi.org/10.1016/j. autcon.2011.04.016

[11] Bęcek K., Gawronek P., Klapa P. et al., Modelowanie i wizualizacja danych 3D na podstawie pomiarów fotogrametrycznych $i$ skaningu laserowego. Rzeszów, 2015.

[12] Chiabrando F., Lo Turco M., Rinaudo F., "Modeling the decay in an HBIM starting from 3D point clouds. A followed approach for cultural heritage knowledge", ISPRS - International Archives of the Photogrammetry, Remote Sensing and Spatial Information Sciences, volume XLII-2/W5, 2017, pp. 605-612. https://doi.org/10.5194/isprs-archives-XLII-2-W5-605-2017

[13] Campi M., Di Luggo A., Scandurra S., "3d modeling for the knowledge of architectural heritage and virtual reconstruction of its historical memory", ISPRS - International Archives of the Photogrammetry, Remote Sensing and Spatial Information Sciences, volume XLII-2/W3, 2017, pp. 133-139. https://doi.org/10.5194/isprs-archives-XLII-2-W3-133-2017

[14] Kim Ch., Son H., Kim Ch., „Fully automated registration of 3D data to a 3D CAD model for project progress monitoring", Automation in Construction, volume 35, 2013, pp. 587-594. https:// doi.org/10.1016/j.autcon.2013.01.005 
[15] FARO Knowledge Base, “As-Built”. Available: https://knowledge.faro.com/Software/As-Built [Accessed: 18 Dec 2020]

[16] Son H., Bosché F., Kim Ch., "As-built data acquisition and its use in production monitoring and automated layout of civil infrastructure: A survey", Advanced Engineering Informatics, Volume 29, Issue 2, 2015, pp. 172-183. https://doi.org/10.1016/J.AEI.2015.01.009

[17] Kotula F., „Kaplica myśliwska pod wezwaniem św. Huberta w Miłocinie k. Rzeszowa”, Ochrona Zabytków, 4/1-2 (12-13), 1951, pp. 95-98

[18] Karta ewidencyjna, Kaplica p.w. św. Huberta, oprac.: Malczewski J., 1993, Archiwum Wojewódzkiego Urzędu Ochrony Zabytków Delegatury w Rzeszowie.

[19] Karta ewidencyjna, Kaplica p.w. św. Huberta, oprac.: Żurawska T., 1959, Archiwum Wojewódzkiego Urzędu Ochrony Zabytków Delegatury $w$ Rzeszowie. 
